\title{
PCIM: A Project Control and Inhibiting-Factors Management Model
}

Yakubu Olawale, Ph.D., MCIOB, MAPM and Ming Sun, Ph.D. (Professor)

\begin{abstract}
In construction projects, the aim of project control is to ensure projects finish on time, within budget and achieve other project objectives. During the last few decades, numerous project control methods have been developed and adopted by project managers in practice. However, many of the existing methods focus on describing what the processes and tasks of project control are; not on how these tasks should be carried out. There is also a potential gap between principles that underlies these methods and project control practice. As a result, time and cost overruns are still common in construction projects partly due to deficiencies of the existing project control methods and difficulties in implementing them. This paper describes a new project cost and time control model, developed through a study involving extensive interaction with construction practitioners in the UK, which better reflects the real needs of project managers. A set of good practice checklist is also developed to facilitate the implementation of the model.
\end{abstract}

\section{Introduction}

On-time and within-budget are common requirements for all construction projects. Unfortunately, in reality many projects suffer from delays and budget overspends. Overcoming this problem requires effective project cost and time control. Project control is often a complex task undertaken by project managers in practice. During the last few decades, numerous planning and control techniques, such as Gantt Bar Chart, Program Evaluation and Review Technique (PERT), Earned Value Analysis, Critical Path Method (CPM), have been developed. A variety of 
software packages have also become available to support the application of these project control methods, for example Microsoft Project, Asta Power Project, Primavera, etc. The problem is that these techniques, though beneficial, would always be used as part of a project control process and do not constitute a control process on their own. In practice, project control is a complex and iterative process that is usually achieved in three phases: setting performance standards; comparing actual performance with these standards; then taking necessary corrective actions. It is considered the last logical step in management and during the control stage, the level of performance is compared with the planned objectives to find any deviation and consequently act on it (Pellicer, 2005). In recent years, numerous empirical studies have been conducted by various researchers in a bid to improve project control. Published literature in the area can be discussed under the following topics: project management bodies of knowledge in the area of project control; the nature and scope of project control; the importance of project control; success factors in project management control; project control systems; and synthesis of requirements for project control (Rozenes et al, 2006). As the main focus of this paper is introduction to a newly developed project control model and its application, literature review is concentrated on success factors of project control and project control systems in the following order: project success factors; IT based project control systems; mathematically oriented project control methods; and process based project control methods.

To improve project control, it is essential to understand the key factors that influence this process. Gao et al (2002) identified specific contributors to project budget and/or schedule performance success as: team-building activities; core management group for small projects; maintenance contracts concurrent with small projects; standard processes and front-end planning

Cite as: Olawale, Y. and Sun, M. (2012) PCIM: A project control and inhibiting-factors management model. ASCE Journal of Management in Engineering doi:10.1061/(ASCE)ME.1943-5479.0000125 (Feb. 21, 2012).

Page 2 
use of checklists. Iyer and Jha (2005), through a questionnaire survey, found coordination among project participants as the most important success or failure factor. Sohail and Baldwin (2004) established 69 performance indicators that can be used as a set of measurement to monitor projects and classified these performance indicators as: general indicators, time indicators, cost indicator, quality indicators, inter-organisational co-operation and socioeconomic indicators. Similarly, Ling et al (2009) established 24 project management practices that are significantly correlated with project performance and recommended that emphasis must be given to scope management in order to achieve superior project performance. Chan et al (2001) identified project team commitment, client's competencies and contractor's competencies as critical in explaining overall performance of design and build projects. Ling (2004) found that contractor's track record for completion on time, affect up to six performance metrics including the time performance of a project. Lee et al (2005) revealed that pre-project planning, project change management, and design/information technology are critical practices with important impacts on both cost and schedule performance of projects. White and Fortune (2002) through a questionnaire survey found that clear goals and objectives; support from senior management; and adequate funds/resources are the three leading critical project success factors. Finally, Milosevic and Patanakul (2005) investigated the impact of standardized project management practices on project performance and identified standardized project management tools; leadership skills; and processes as factors that may have a higher impact on project success.

One area of research effort is the development of IT based project control systems based on established control techniques. For example, Benjaoran (2009) developed a new system for cost control based on the earned value concept, which was specifically aimed at small and medium 
sized companies. Similarly, Gorog (2009) designed a comprehensive model for planning and controlling contractor cash-flow by adapting the earned value management techniques. Using the same earned value concept, Jung and Kang (2007) developed a system that can alleviate workload, enhance accuracy, and sustain adaptability through automated formulating of work packages by using historical database and the automation of progress information gathering in order to reduce the excessive managerial efforts required to update and analyze earned value information during project control. Alshawi and Hassan (1999) developed the CONPLAN model in the argument that the planning process will not fulfill its potential role as a control and a decision making tool without proper integration. It should however be pointed out that the detailed and elaborate model was developed mainly to aid planning rather than overall project control. Kaka (1999) developed a stochastic based S-curved model that can use past projects performances to monitor future projects, it was however noted that the developed model cannot be used as an alternative to project control but mainly to highlight significant discrepancies in performance, in other words a monitoring tool. Barraza and Bueno (2007) pointed out that standard control methods, such as the earned value method apply a deterministic approach which may be insufficient as they ignore the variable nature of projects. A probabilistic project control model that uses performance control limit curves and stochastic S-curves was developed, noting that it will be more effective for projects with uncertain performance behaviour.

Other researchers went beyond simple implementation of project control techniques by proposing new project control methods. Cho et al (2010) argued for the need for an integration model that facilitates efficient planning of repetitive construction processes. Hence, a model was developed by integrating the schedule and cost information with resource information inputted to 
the project. It was however recommended that since the developed model is only applicable to repetitive construction processes, an integration model that can carter for an entire project should be developed. A similar repetitive projects centric study was conducted by Hyari and El-Rayes (2006) who developed a multi-objective optimization model to support the planning and scheduling of repetitive construction projects. Leu and Lin (2008) adopted a quantitative approach based on the statistical process control (SPC) chart technique to refine and improve the performance of traditional earned value management technique. Nassar et al (2005) also developed a model based on the SPC method in a bid to evaluate cost overruns of asphalt paving project. The problem is that although the SPC could identify the special causes of deviations but how it could be used to control the identified deviations was not specified, the data used was also only from asphalt paving projects. Rozenes et al (2004) developed a project control system that quantifies deviations from the planning phase to the execution phase with respect to global project control specifications (GPCS) which would present project performance in all dimensions of operations, thereby drawing attention to poor performance. Falco and Macchiaroli (1998) on the other hand argued that monitoring and control actions arises because projects are dynamic in nature and recommended different allocations of control points through the application of the effort function (a non-linear function of the total number of active operations) and total slack time. The dynamic nature of projects also informed the study of Fena-Mora and Li (2001) who developed the dynamic planning and control methodology which integrates the application axiomatic design concepts, concurrent engineering, graphical evaluation and review technique (GERT) and system dynamic modelling. However, it is a complex system, and may not be readily adopted for ordinary projects; for example GERT, just one of the components of the developed model is rarely used in practice (Egbu et al, 1998).

Cite as: Olawale, Y. and Sun, M. (2012) PCIM: A project control and inhibiting-factors management model. ASCE Journal of Management in Engineering doi:10.1061/(ASCE)ME.1943-5479.0000125 (Feb. 21, 2012).

Page 5 
Finally, another area of research, which is most relevant to this study, is process based project control models. The basis for many of these studies is the well-known Deming's Plan-Do-CheckAction (PDCA) wheel (Deming, 2000). Deming's PDCA wheel describes a management process, originally used for quality control purposes. Some researchers attempted to adopt it for construction project control while acknowledging the need for modifications. For example Platje and Wadman (1998) criticized the PDCA model as having the drawback of no time-dependent element and not fully describing the whole planning and control situation or its development in time. The PDCA cycle was subsequently modified to Plan, Implement, Do, Check, Act and Management (PIDCAM) but just adding two additional stages to the classical PDCA model is not enough to improve the control process if other measures are not put in place during the implementation of the model. Watson and Davis (2002) echoed Platje and Wadman (1998) criticism, noting the lack of progression of each cycle as a limitation of Deming's PDCA.

Literature review revealed some weaknesses of these existing project control studies and developed models. (1) Many existing systems are more geared towards planning rather than towards control. While the importance of planning cannot be under emphasized; but during project control process, planning is only the starting point. (2) The process based control models, such as PDCA and its variations, only describe WHAT not HOW. Hence although a number of studies describe what an ideal project control process should look like diagrammatically, mathematically or isolation of project management control success factor, there is not much work done on how they can be utilized in practice. (3) Many studies are not well grounded in project control practice. Most of the developed models have not involved practitioners in their 
development. Therefore, it is questionable how accurately they reflect the real problems being faced by project management practitioners during project control practice. These conclusions underlie the need for an improved cost and time control model and the rationale for this study. The development of a new Project Control and Inhibiting-factors Management (PCIM) model will focus on cost and time control and adopt a collaborative and contingent (situational) approach by involving practitioners in order to draw out their needs, requirements, bottlenecks and current issues in practice.

Unlike many previous studies that have mainly focused on identifying factors that causes project cost and time overrun but not the factors that makes it difficult to control these factors in practice (Hoffman et al, 2007; Shane et al, 2009), this study contributes to revealing the most important factors that inhibit effective control of the cost and time objectives of construction projects in the UK. Additionally, this study goes beyond the identification of project control problems; the developed PCIM model and good practice checklist are geared at mitigating identified project control problems in practice.

Although there have been attempts at developing project control models in the past, they have been rather fragmented in focus with varying objectives such as studying causation and effect, relationship of factors, comparison of techniques, development of computer tools, monitoring tools or isolation of selected practices that can aid project control. Most of these studies have not been directly targeted at practitioners or involved the practitioners in their development. The extensive involvement of practitioners during all three stages of this study is designed to ensure the validity of the findings and the relevance of the outputs. The approach adopted in the 
development of the PCIM model can be referred to as a "practice grounded" research process underlined by the contingent philosophy of developing a theory/explanation to a phenomenon. Following this approach, the situational factors in practice are considered through the involvement of practitioners through the research process in order to draw out their needs, requirements, bottlenecks and current issues in practice so that the research output (the PCIM model) is up-to-date and applicable in practice.

\section{Research Methods and Model Development Process}

Figure 1 illustrates the process of developing the PCIM model during this study. A three stage development approach was adopted, utilizing a combination of quantitative and qualitative methodology, and a range of specific research methods. The main aim of the first stage was to establish a list of top inhibiting factors of project control practice. This was achieved using the quantitative methodology through a questionnaire survey. The second stage, conducted using the qualitative methodology through semi-structured interviews, was to establish construction practitioners' experience in project control and relevant issues. On the basis of the first two stages a PCIM model was developed during the third stage. The model was evaluated and refined through a Delphi process. It is worth mentioning that these three stages are interwoven and dependent on each other. The detail of the main activities performed in each stage of the research is highlighted in the following sections.

Cite as: Olawale, Y. and Sun, M. (2012) PCIM: A project control and inhibiting-factors management model. ASCE Journal of Management in Engineering doi:10.1061/(ASCE)ME.1943-5479.0000125 (Feb. 21, 2012). Page 8 


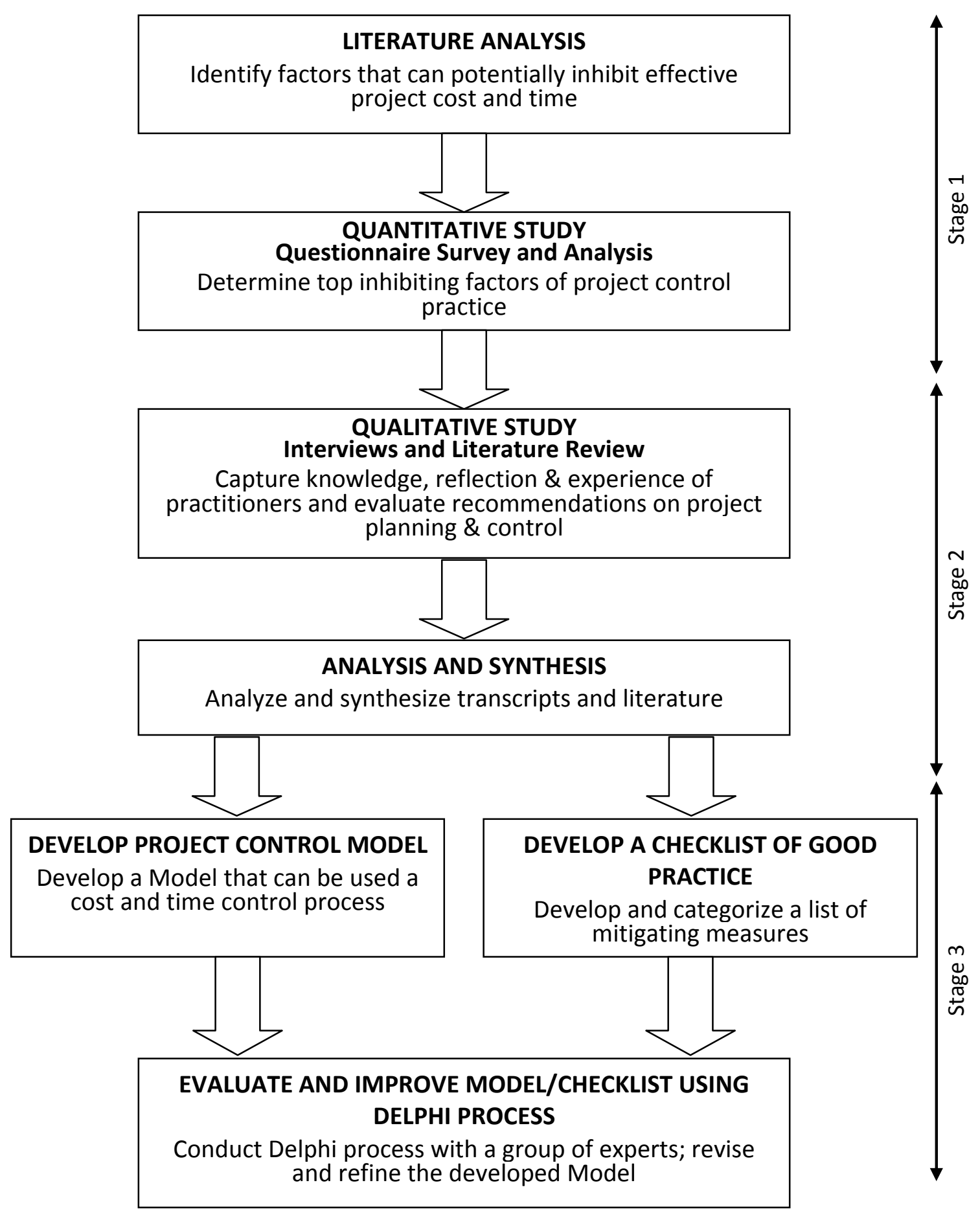

Figure 1: The PCIM Model development process

Cite as: Olawale, Y. and Sun, M. (2012) PCIM: A project control and inhibiting-factors management model. ASCE Journal of Management in Engineering doi:10.1061/(ASCE)ME.1943-5479.0000125 (Feb. 21, 2012). Page 9 


\section{Questionnaire survey}

The aim of the survey is to provide information on the current common practice of time and cost control in the UK construction industry and to establish the the leading factors that hamper practitioners from effectively controlling the cost and time objectives of their project in practice. A thorough review of existing studies was conducted before a questionnaire was developed, which is made up of 22 multiple choice questions. The questionnaire was divided into three sections. The first section sought to obtain information on the general particulars of the respondents and their organisation. The second section was about time overrun, with questions like; "Are your construction activities and projects completed at the planned/scheduled date or do they encounter time overrun?", "How do you determine the durations of your construction activities and your projects?", "Do you use any of the following technique(s) for planning/scheduling and time monitoring/control of tasks of your construction projects?". The third section contained similar questions but specific to cost control practices. One of the questions of particular imporatance to the development of the PCIM model relates to the determination of the leading project control inhibiting factors from the 20 pre-identified facors. These factors were presented to respondents who were asked to rank them as either 'extremely important', 'important', 'unimportant' or 'extremely unimportant' using the question; "Please rate the level of importance for each of the following factors in affecting your ability to effectively control the time of your construction projects.” A similar question was also asked separately about cost control. Respondents were also asked to include and rate other factors they considered necessary for inclusion to the list. Only few additions were made to the list, and in most cases these additions were the same or related to one or more of the 20 factors originally presented to the respondents.

Cite as: Olawale, Y. and Sun, M. (2012) PCIM: A project control and inhibiting-factors management model. ASCE Journal of Management in Engineering doi:10.1061/(ASCE)ME.1943-5479.0000125 (Feb. 21, 2012). Page 10 
250 questionnaires were administered to the top 150 construction contracting companies in the UK by annual turnover and the leading 100 consultancies by the number of professional staff employed/company fee earnings. This list was obtained from the 2006 annual league table published by the Building magazine. 110 questionnaires (44\% overall response rate with 45\% response rate by contractors and $42 \%$ response rate by consultants). $71 \%$ of responding contractors were directors/senior managers and $73 \%$ of responding consultants held similar positions. Respondents had significant years of experience in the construction industry, $64 \%$ of responding contractors had more than 25 years experience and $69 \%$ of responding consultants also had more than 25 years of experience.

The data from the questionnaire was analysed by quantitative means. Relative importance index was used in the analysis to establish the ranking of the factors that affect the ability to control cost and time. A numerical value was assigned to the ratings as follows: 'extremely important' 4, 'important' - 3, 'unimportant' - 2, 'extremely unimportant' - 1. This four-point scale was converted to a Relative Importance Index (RII) for each individual factor. This was calculated using the following formula, as adopted by Chan and Kumaraswamy (1997), Assaf et al (1995) and Iyer and Jha (2005):

$$
\mathrm{RII}=\sum \mathrm{W} \div(\mathrm{H} \times \mathrm{N})
$$

Where $\mathrm{w}$ is the total weight given to each factor by the respondents, which ranges from 1 to 4 and is calculated by an addition of the various weightings given to a factor by the entire 
respondent, $\mathrm{H}$ is the highest ranking available (i.e. 4 in this case) and $\mathrm{N}$ is the total number of respondents that have answered the question. Results of the analysis of questionnaire survey have been presented elaborately in a separate paper (Yakubu and Sun, 2009). Tables 1 and 2 present a summary of the top 20 inhibiting factors for time and cost control respectively. The inferences from the analysis were carried to the next stage of the research for further investigation.

Table 1 Ranking of factors inhibiting effective project time control

\begin{tabular}{l|ll}
\hline \multirow{2}{*}{ Time control inhibiting factors } & \multicolumn{2}{l}{ All responses } \\
\cline { 2 - 3 } Rank & RII \\
\hline Design changes & 1 & 0.94 \\
Inaccurate evaluation of projects time/duration & 2 & 0.86 \\
Complexity of works & 3 & 0.86 \\
Risk and uncertainty associated with projects & 4 & 0.85 \\
Non performance of subcontractors and nominated suppliers & 5 & 0.85 \\
Lack of proper training and experience of PM & 6 & 0.78 \\
Discrepancies in contract documentation & 7 & 0.77 \\
Low skilled manpower & 8 & 0.74 \\
Conflict between project parties & 9 & 0.74 \\
Unpredictable weather conditions & 10 & 0.74 \\
Financing and payment for completed works & 11 & 0.73 \\
Contract and specification interpretation disagreement & 12 & 0.71 \\
Dependency on imported materials & 13 & 0.66 \\
Lack of appropriate software & 14 & 0.61 \\
Inflation of prices & 15 & 0.58 \\
Weak regulation and control & 16 & 0.55 \\
Project fraud and corruption & 17 & 0.5 \\
Unstable government policies & 18 & 0.47 \\
Unstable interest rate & 19 & 0.46 \\
Fluctuation of currency/exchange rate & 20 & 0.45 \\
\hline & & \\
\hline
\end{tabular}

Cite as: Olawale, Y. and Sun, M. (2012) PCIM: A project control and inhibiting-factors management model. ASCE Journal of Management in Engineering doi:10.1061/(ASCE)ME.1943-5479.0000125 (Feb. 21, 2012). 
Table 2 Ranking of factors inhibiting effective project cost control

\begin{tabular}{l|ll}
\hline \multirow{2}{*}{ Cost control inhibiting factors } & \multicolumn{2}{|l}{ All responses } \\
\cline { 2 - 3 } Design changes & 1 & Rank \\
\hline Risk and uncertainty associated with projects & 2 & 0.94 \\
Inaccurate evaluation of projects time/duration & 3 & 0.89 \\
Non performance of subcontractors and nominated suppliers & 4 & 0.82 \\
Complexity of works & 5 & 0.81 \\
Conflict between project parties & 6 & 0.81 \\
Discrepancies in contract documentation & 7 & 0.80 \\
Contract and specification interpretation disagreement & 8 & 0.80 \\
Inflation of prices & 9 & 0.79 \\
Financing and payment for completed works & 10 & 0.78 \\
Lack of proper training and experience on PM & 11 & 0.77 \\
Low skilled manpower & 12 & 0.69 \\
Unpredictable weather conditions & 13 & 0.68 \\
Dependency on imported materials & 14 & 0.65 \\
Lack of appropriate software & 15 & 0.62 \\
Unstable interest rate & 16 & 0.59 \\
Fluctuation of currency/exchange rate & 17 & 0.58 \\
Weak regulation and control & 18 & 0.58 \\
Project fraud and corruption & 19 & 0.55 \\
Unstable government policies & 20 & 0.48 \\
\hline
\end{tabular}

\section{Interviews}

The second stage of the PCIM development process involved the use of semi-structured interviews. The aim was to explore the topical issues revealed by the questionnaire survey and to further unveil the experiences of practitioners in relation to project control in greater depth. The same population used for the survey stage of the research was used. A total of 15 companies

Cite as: Olawale, Y. and Sun, M. (2012) PCIM: A project control and inhibiting-factors management model. ASCE Journal of Management in Engineering doi:10.1061/(ASCE)ME.1943-5479.0000125 (Feb. 21, 2012). Page 13 
offered relevant practitioners for interviews ranging from construction directors, project directors, commercial directors, to senior project managers.

The responded companies were a mix of contractors and consultants with varying but quite often similar kind of projects. The total professional experience of the 15 interviewees is 402 years (average experience of 26.8 years). Majority of the interviewees are senior employees of their companies and many of these companies are large organizations with national and international coverage. Table 3 provides more information on each of the interviewees. The use of semistructured interviews provided a rich source of information on the experiences of practitioners in relation to project control in practice such as how the prevailing cost and time control techniques are currently being used in practice; the main problems/bottlenecks encountered during the usage; the broad processes and practices underpinning their usage; and the qualities they would like to see in any developed project control model.

These interviews are recorded and transcribed. Extensive qualitative analysis of the transcripts was carried out and inferences made. This led to the development of an initial project cost and time control model and an extensive checklist of good practice. The good practices were not directly cherry picked from the interviewees' responses; instead they were developed through an iterative process involving analysis of the interview transcripts and through varying quotes from the interviews where some emerging problems or needs of the interviewees were revealed. These problems were critically evaluated taking into consideration of previous literature review in the subject area, the result of the questionnaire survey etc.

Cite as: Olawale, Y. and Sun, M. (2012) PCIM: A project control and inhibiting-factors management model. ASCE Journal of Management in Engineering doi:10.1061/(ASCE)ME.1943-5479.0000125 (Feb. 21, 2012).

Page 14 
Table 3 Information of interviewees

\begin{tabular}{|c|c|c|c|c|c|}
\hline No. & Roles & Years* & $\begin{array}{l}\text { Company } \\
\text { type }\end{array}$ & Project types & $\begin{array}{l}\text { Interview } \\
\text { duration }\end{array}$ \\
\hline 1 & $\begin{array}{l}\text { Senior general } \\
\text { project manager }\end{array}$ & 30 & $\begin{array}{l}\text { Main } \\
\text { contractor }\end{array}$ & Construction, civil engineering, nuclear etc. & $50 \mathrm{~min}$ \\
\hline 2 & $\begin{array}{l}\text { Commercial } \\
\text { director }\end{array}$ & 25 & $\begin{array}{l}\text { Main } \\
\text { contractor }\end{array}$ & $\begin{array}{l}\text { Building construction, telecommunication, } \\
\text { infrastructure, civil engineering }\end{array}$ & $40 \mathrm{~min}$ \\
\hline 3 & Director & 25 & Contractor & Building and engineering services & $30 \mathrm{~min}$ \\
\hline 4 & Associate director & 28 & Consultant & Construction & $30 \mathrm{~min}$ \\
\hline 5 & $\begin{array}{l}\text { Senior contracts } \\
\text { manager }\end{array}$ & 24 & $\begin{array}{l}\text { Main } \\
\text { contractor }\end{array}$ & Social housing/regeneration & $40 \mathrm{~min}$ \\
\hline 6 & Planning director & 28 & $\begin{array}{l}\text { Main } \\
\text { contractor }\end{array}$ & $\begin{array}{l}\text { Building, Transport infrastructure, Civil } \\
\text { engineering }\end{array}$ & $50 \mathrm{~min}$ \\
\hline 7 & Director & 45 & Consultant & Construction & $35 \mathrm{~min}$ \\
\hline 8 & Head of planning & 20 & $\begin{array}{l}\text { Main } \\
\text { contractor }\end{array}$ & Building construction & $15 \mathrm{~min}$ \\
\hline 9 & Regional manager & 34 & $\begin{array}{l}\text { Main } \\
\text { contractor }\end{array}$ & Building, construction and civil engineering & $20 \mathrm{~min}$ \\
\hline 10 & Director & 25 & $\begin{array}{l}\text { Main } \\
\text { contractor }\end{array}$ & Building construction & $30 \mathrm{~min}$ \\
\hline 11 & $\begin{array}{l}\text { Senior programme } \\
\text { manager }\end{array}$ & 11 & Consortium & Infrastructure, construction & $45 \mathrm{~min}$ \\
\hline 12 & Director & 40 & $\begin{array}{l}\text { Main } \\
\text { contractor }\end{array}$ & Building construction and civil engineering & $35 \mathrm{~min}$ \\
\hline 13 & $\begin{array}{l}\text { Head of project } \\
\text { planning }\end{array}$ & 20 & $\begin{array}{l}\text { Main } \\
\text { contractor }\end{array}$ & Building and construction & $30 \mathrm{~min}$ \\
\hline 14 & Director & 22 & $\begin{array}{l}\text { Consultants } \\
\text { and } \\
\text { contractor }\end{array}$ & $\begin{array}{l}\text { Construction, infrastructure and } \\
\text { engineering }\end{array}$ & $30 \mathrm{~min}$ \\
\hline 15 & Director & 25 & $\begin{array}{l}\text { Main } \\
\text { contractor }\end{array}$ & Construction & $30 \mathrm{~min}$ \\
\hline
\end{tabular}

* Number of years of experience in the construction industry

Cite as: Olawale, Y. and Sun, M. (2012) PCIM: A project control and inhibiting-factors management model. ASCE Journal of Management in Engineering doi:10.1061/(ASCE)ME.1943-5479.0000125 (Feb. 21, 2012). Page 15 


\section{Model development and Delphi method}

The model development process commenced with a detailed analysis of the individual processes of cost and time control revealed during the survey and interview stages of the research and modeling them to produce an initial descriptive model. The preliminary model was refined by the researchers based on synthesis of the findings and analysis of the questionnaire survey and interviews, as well as further literature analysis. The improved model was then presented to practitioners for evaluation using the Delphi technique. This process is detailed in the Evaluation section later in this paper. The final Project Control and Inhibiting-factors Management (PCIM)

Model is presented in Figure 2. The rest of the paper provides detailed description of the model.

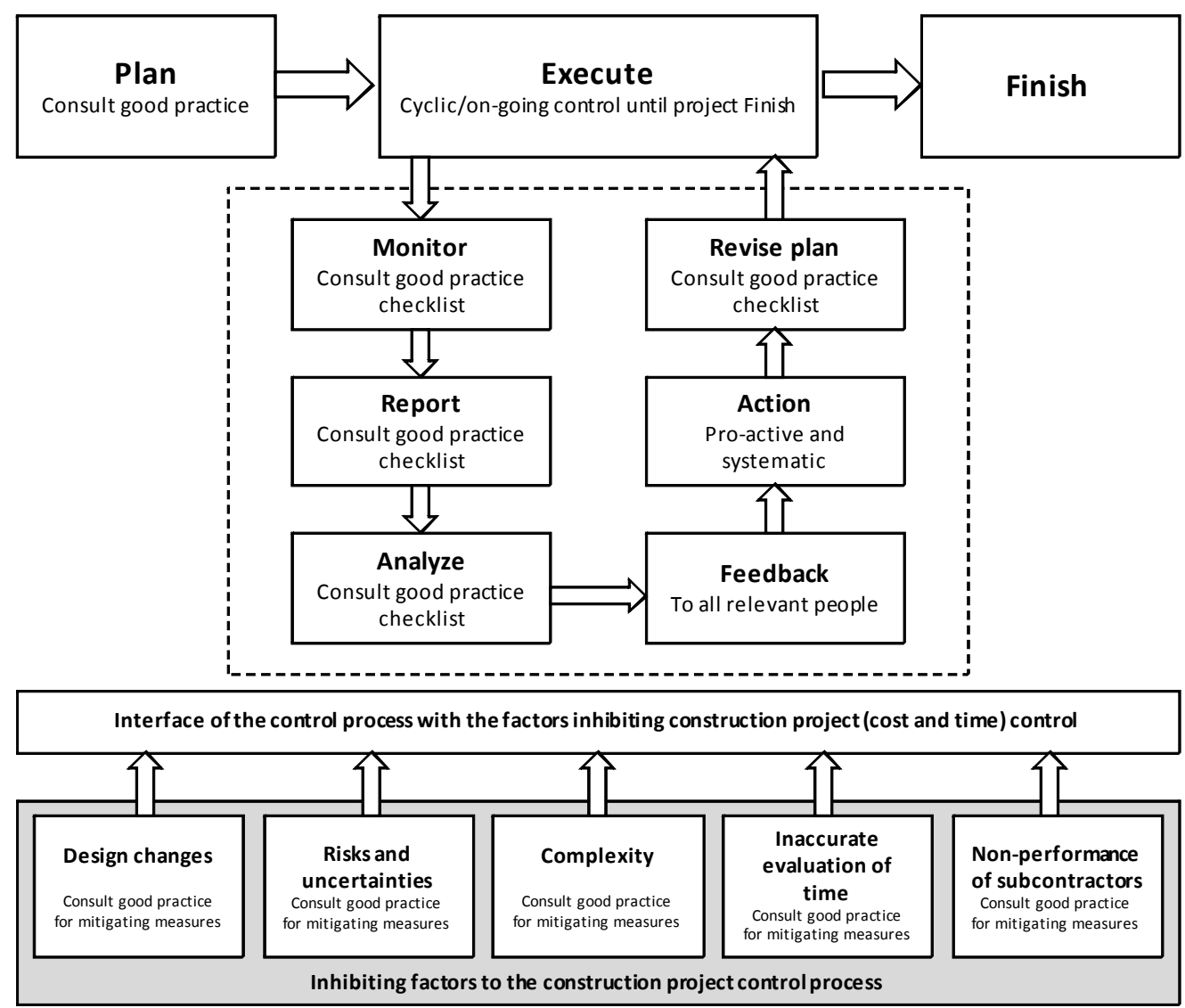

Figure 2: A Project Control and Inhibiting-Factors Management (PCIM) Model

Cite as: Olawale, Y. and Sun, M. (2012) PCIM: A project control and inhibiting-factors management model. ASCE Journal of Management in Engineering doi:10.1061/(ASCE)ME.1943-5479.0000125 (Feb. 21, 2012). Page 16 


\section{Project Control and Inhibiting-factors Management (PCIM) Model}

The PCIM model is made up of three main sections: the top section is the main phases that a project goes through (Planning, Execute and Finish); the middle section is the main project control steps (Monitor, Report, Analyze, Feedback, Action, and Revise Plan); while the bottom section reflects the fact that project control is not a closed system and is often inhibited by some factors. The leading project control inhibiting-factors in this model are design changes, risks and uncertainties, complexity, inaccurate evaluation of time and non-performance of subcontractors. This model includes a set of good practice checklist, which provides advice on mitigating each of these inhibiting factors. The processes of the PCIM model are described in the following sections.

\section{Plan}

Planning refers to the determination of objectives, identifying activities to be performed, resources and methods to be used to perform the task (Floyd 2004). The PCIM model suggests that project control should start at the Planning stage of a project. One of the revelations of this study is that quite often project management practitioners do not plan how a project will be controlled at the outset of the project. During the Planning stage of the project a lot of effort is often spent on planning how the project will be executed. For example it was revealed that various types of schedule of works are deplored to sequence the activities to be performed. Detailed cost estimates and cost plans are also produced. However, these Plans are often developed without giving prior thought to how they will be used for project cost and time control. Fewings (2005) alluded to this by pointing out that the control system is critical to the health of the project and its choice should influence the planning process rather than the other 
way round. The PCIM model identifies this problem and proposes that during the planning stage of a construction project, in addition to the production of the schedule of works and cost estimates, consideration should be given to how the project will be controlled during the Execution stage. Therefore a very important part of the model is the preparation of a document that details how the project will be controlled during the planning phase of the project. This document has been referred to as the project control implementation document (PCID). It will set out the following:

- Project control tools and techniques to be used during the project

- $\quad$ The frequency of monitoring and reporting

- The destination of the reports

- $\quad$ The templates of the reports

- Duties of the project team as it relates to controlling the project

- Other information deemed necessary for effective control

The PCID will be prepared by the project manager in consultation with the rest of the project team and it will be circulated to the whole project team including the site management team. The PCID for each project should be reviewed regularly by the project manager to ensure that the project is being controlled as planned.

\section{Execute}

The model moves from Planning to the Execution phase of the project. The Execution phase of a project is where the plan is put into practice in order to bring the concept into reality. It is during this stage where control of cost and time is mostly needed because it is the most risky phase of 
the project where things can often go wrong and where the plan made at the outset is put to test. Project control during this phase consists of a cyclic and iterative process of the following activities.

\section{Monitor}

After the project has been Planned and the plan put into Execution, this original plan needs to be Monitored during the Execution stage. According to Otieno (2000), monitoring is the process that provides information and ensures the use of such information by management to assess project effects both intentionally and unintentionally and their impact. It aims to determine whether or not the intended objectives have been met. The Monitoring step of the PCIM model, first of all, suggests that Monitoring should be a distinct step in the control cycle as opposed to the prevalent practice where monitoring is barely embarked upon by the site management team; and control seems to move straight from Planning to Reporting by site based quantity surveyors. While having site-based quantity surveyors is not being discounted and can provide good reports, it will be better if Monitoring is incorporated into the practices or duties of the site management team.

\section{Report}

The next step of the model is Reporting. Reporting provides a straightforward statement of the work accomplished, predicts future accomplishment in terms of the project cost and schedule, and measures actual accomplishments against goals set forth in the plan. It also reviews current and potential problems and indicates management action underway to overcome the effects of the problems (Barrie and Paulson 1984). It was shown in practice that while cost control

Cite as: Olawale, Y. and Sun, M. (2012) PCIM: A project control and inhibiting-factors management model. ASCE Journal of Management in Engineering doi:10.1061/(ASCE)ME.1943-5479.0000125 (Feb. 21, 2012).

Page 19 
reporting seems robust as it is often done by site based quantity surveyor, the Reporting on time control is at best loose. For example one of the interviewees (a director from a construction consultancy) commented about their reporting regime as follows:

“...we get a very simple Gantt chart from the contractor and one can very quickly do a progress line against it....it's just a narrative attached to the cost report saying this is how we are getting on, on site...” This seems to confirm the findings of Xiao and Proverbs (2002) who found that Japanese contractors performed better than UK and US contractors in terms of shorter construction times and noted that one of the reasons for this may be attributed to the extensive use of networks for schedule control in Japan, unlike UK and US practice where the use of simple Gantt charts was found to be more prevalent.

The PCIM model advocates a more structured approach through a number of measures such as the incorporation of a reporting system embedded in the PCID right at the project outset. This specifies the reporting templates, reporting cycle, destination of reports; and ensures that reporting is not solely achieved through progress meetings but is systematic and regular. Simple software packages should also be used to aid reporting and to allow reports to be sent to the departments responsible for collating and analyzing these reports. The PCIM model also proposes that time and cost reporting should not be done separately but together. This can be achieved through the use of reporting templates that contain both cost and time information in order to aid the integration of cost and time control. This will combat the prevailing practice where management of time is left to the planning department and management of the cost estimate/cost plan is left to the quantity surveying department and the 'two never meet'.

Cite as: Olawale, Y. and Sun, M. (2012) PCIM: A project control and inhibiting-factors management model. ASCE Journal of Management in Engineering doi:10.1061/(ASCE)ME.1943-5479.0000125 (Feb. 21, 2012).

Page 20 


\section{Analyze}

From Reporting, next in the PCIM model is the Analyzing step, during which cost and time information contained in the submitted report is analyzed. According to Turner (1999), having gathered the data, the team must determine whether the project is behaving as predicted, and if not, calculate the size and impact of the variances. This is one of the most important steps during the control process because if done properly the analysis step could go a long way in mending a failing project. The problem with this step in practice is that the full potential of Analysis is not explored. It was revealed that the analysis step is more of interpretation of the information reported rather than Analysis. The prevailing practice often does not integrate cost and time during this important step. This is usually not an effective approach. According to Jung and Woo (2004), cost and scheduling are closely interrelated, because they share a lot of common data in their controlling processes hence, integrating cost and schedule control functions provides an effective tool for monitoring the construction process. In the words of one of the interviewees (a director at a contracting organization):

“...project controls, you've alluded to time and cost, so pretty much everywhere I've been, there has been a little office with the planners (schedulers) in, there has been a little office with the cost or commercial people in and never the two shall meet... so project control is a difficult thing that either organizations don't want to get to, don't see the benefits of getting to..."

Not integrating cost and time analysis will invariably generate results that are not very useful for the next step of the control process because any action to bring the project back on track will often have a cost implication. The PCIM model corrects these shortcomings by advocating that techniques that combine cost and time data are used during Analysis in order to foster the 
integration of cost and time controls; secondly the model goes beyond just interpretation but advocates trending and the use of the results obtained to forecast the future performance of the project. A useful technique that can be used to achieve this is the earned value method or for more complex projects the PERT/Cost technique.

The earned value method is very effective for most projects and provides the added benefit of utilizing both cost and time information. It takes into account the work completed, the time taken and the costs incurred to complete the project and it helps to evaluate and control project risk by measuring project progress in monetary terms (Vandevoorde and Vanhoucke 2005). This provides results that are useful for both the cost and time objectives of the project thereby perfectly allowing the integration of both cost and time. In addition, it was revealed from the study that one of the essential qualities of any developed project control model as clamored for by practitioners is the integration of cost and time during the project control process. Earned value analysis is well documented in project management hence it is not the intention to describe it in this paper.

\section{Feedback}

From the analysis step the PCIM model advocates a dedicated Feedback action. Feedback is the process of disseminating the result of the analysis conducted on the information from the monitoring and reporting steps to all the necessary participants and relevant stakeholders involved with the project. This is very important during the project control process, but interestingly this is often not reiterated in most project cost and time control models. This is also found to be missing from the prevailing control process in practice. The results of the analysis 
step need to be transmitted to everybody who has an action to take otherwise the effort that has been put into collecting information, Reporting and Analyzing will be in vain. The study revealed that in practice there is no systematic way of disseminating the findings of the Analysis step. What normally happens is that if Analysis reveals that action(s) are to bring the project back on track, quite often, at best only ad hoc meetings are held to discuss the situation.

The PCIM model proposes that irrespective of the results of the Analysis, systems and processes should be put in place to feedback the findings to the site and project management teams. In practice, transfer of project control information is often only one way; from the site to the project office. The project office rarely provides feedback on their findings to the site team with the exception of when the findings are negative. The PCIM model suggests the use of a feedback report from the project control team sent at set periods to the site team. This will go a long way in motivating the site team that the monitoring and reporting they carry out and transmit to the project office is not useless information but is actually being used. This will also instill a project control culture in the organization. This feedback report should also be sent to senior managers, and the project decision makers that can act on the findings of the analysis stage. Finally, having a dedicated Feedback procedure ensures that information is transmitted quickly and efficiently and is not left on the desk until it becomes obsolete and useless.

\section{Action}

The PCIM model moves from the Feedback to Action. This step ensures that information revealed from the Analysis step is put into practice. In order to close the control loop, the team must take effective action to overcome any variances. This involves identifying and evaluating

Cite as: Olawale, Y. and Sun, M. (2012) PCIM: A project control and inhibiting-factors management model. ASCE Journal of Management in Engineering doi:10.1061/(ASCE)ME.1943-5479.0000125 (Feb. 21, 2012).

Page 23 
alternative courses of action for resolving a perceived problem situation. The objective of action is to produce a timely and practical plan (for carrying out each activity), which conforms to the overall project plans and cost estimate and current knowledge of the project (Mawdesley et al 1997). The PCIM model specifically points out the fact that actions should not only be reactive but proactive. The study revealed that in the prevailing project control models used in practice, action is mostly reactive. In other words, action is only taken to correct things that have gone wrong. Reactive actions are often not effective during project control hence the PCIM model advocates that action should not only be reactive but proactive as well. Information generated during Analysis should be able to highlight possible problems and plan actions well in advance instead of waiting nearer problems occur or even worse after they have occurred (as it's often the case in practice); action should be taken immediately if possible. The PCIM model also advocates that the process of acting should not be haphazard, but should be controlled and systematic. Acting systematically would, for example, involves conducting an impact analysis on the action that will be taken before acting. Some actions may create risks and problems in the future; some actions may cause delays to the project or they may incur cost increases or may raise quality issues. If actions are not systematic, not all the members of the project team are aware of the action and this is counter-productive. Hence systematic approach is essential when deciding on the best action to take. Notification needs to be given to all involved in this Action and they then should plan together and holistically how the Action will be implemented.

\section{Revise Plan}

The PCIM model moves from Action into Revised Plan. Revision of plan involves the updating of the previous project plan to reflect the impact of any action taken as a result of the analysis

Cite as: Olawale, Y. and Sun, M. (2012) PCIM: A project control and inhibiting-factors management model. ASCE Journal of Management in Engineering doi:10.1061/(ASCE)ME.1943-5479.0000125 (Feb. 21, 2012).

Page 24 
conducted on the project. This has been treated as a separate step instead of tagging it to the original planning step (as often the case in practice) because the PCIM model recognizes that this is a process that requires due diligence. This study revealed that in practice when action is taken the status quo often resumes and the revisions of the schedule of works are produced by just updating the action that has already been taken or updating the cost plan and budget. The Revise Plan step in the PCIM model goes beyond just the updating of the old plan. This is because the actions that are taken will often have an impact on the remaining tasks of the project. Therefore, the revision of the schedule and cost plan needs to be more rigorous than just updating. It is worth noting that the initial plan should always be kept as a baseline while the revised plan should be used for continuing the project. Revise Plan marks the end of one iteration of a cyclic and iterative process, which should be repeated continuously while the project is still being executed.

\section{Finish}

Finally, the model moves to the Finish step. This is when the project has been completed and the original conceived plan or an iteratively revised plan accepted by all parties during the course of the project has been achieved.

\section{Project Control Inhibiting Factors}

The next section of the PCIM model shows the inhibitors to the cost and time control process. As mentioned earlier, these inhibiting factors have been identified in this study through a questionnaire survey (Tables 1 and 2). From the two tables it is evident that the leading five factors that inhibited time control are also the leading five factors inhibiting cost control. A

Cite as: Olawale, Y. and Sun, M. (2012) PCIM: A project control and inhibiting-factors management model. ASCE Journal of Management in Engineering doi:10.1061/(ASCE)ME.1943-5479.0000125 (Feb. 21, 2012).

Page 25 
similar conclusion was reached by Chang (2002) study of four completed projects in California where it was found that it is difficult to separate the reasons causing overrun into that of cost and schedule but found that the reasons for cost increases are normally also the reasons for time extensions.

These five leading inhibiting-factors identified are design changes, risk and uncertainty, inaccurate evaluation of project time duration, complexity of works and non-performance of subcontractors. These five factors, because of their importance to cost and time control, were taken to the Interview stage of the research to ascertain their importance to practitioners. At the end of the phase, a set of good practice checklist has been developed to help mitigate negative impact of each of these five inhibiting factors. Yakubu and Sun (2010) has provided a detailed account of this phase of the research.

\section{Good Practice Checklist}

The final ingredient of the PCIM model is a checklist of good practice. According to Angelides (1999) good business practices linked with good technical practices are important for project management in a number of ways including for the fact that they provide incremental improvement, innovation and a process view of a project, which breaks down the barriers between the groups involved in a project, establishing common goals and ensuring optimization. Taking a cue from this, it is obvious that modeling the control steps is only half the story of the control process in practice because any developed model still depends on people to put it into practice. This study found that one of the problems of project control in practice is that many project managers often lack a sense of direction and guidance of what to do. In view of this, this

Cite as: Olawale, Y. and Sun, M. (2012) PCIM: A project control and inhibiting-factors management model. ASCE Journal of Management in Engineering doi:10.1061/(ASCE)ME.1943-5479.0000125 (Feb. 21, 2012).

Page 26 
research went further than most previous studies by developing a 'good practice checklist' for the major steps of the control process (plan, monitor, report and analyze) and mitigating practices for the identified leading project control inhibiting-factors to provide guidance to user.

The developed good practice checklists are an integral part of the PCIM model. They were developed through a three staged research process, involving (1) literature review; (2) questionnaire survey, analysis and synthesis; and finally (3) semi-structured interviews with practitioners to ensure the practical relevance of the developed checklists by drawing from the real life experiences of interviewees. Table 4 shows an example of the checklist developed for the inhibiting-factor - "design changes” during the project control process. All together a set of 155 good practices was developed, 65 practices for the project control steps and 90 practices as mitigating measures for the leading project control inhibiting factors. Full explanation of these checklists has been presented in Olawale and Sun, (2010). It should be pointed out that these good practice checklists are by no means exhaustive. Construction companies and individual practitioners can add additional good practices to the existing checklists or create new checklists for other inhibiting factors which might be particularly important to them. The main purpose of these checklists is to highlight the importance of showing project managers not only what to do but also how to do them.

Cite as: Olawale, Y. and Sun, M. (2012) PCIM: A project control and inhibiting-factors management model. ASCE Journal of Management in Engineering doi:10.1061/(ASCE)ME.1943-5479.0000125 (Feb. 21, 2012). 
Table 4 An example of one the good practice checklists of the PCIM Model

\section{Design changes good practice checklist}

1. Clear distinction between a design change and a design development at the outset of a project

2. Ensuring the cause of a design change is always determined

3. Determination of the provision of the design change within the contract

4. Identification of potential design changes as a risk and devising a strategy for managing the risk especially in design and build projects

5. Ensuring the time and cost implication of a design change is always determined and agreed before going ahead with the change whenever possible.

6. Notification of all the relevant project parties of how they will be impacted and the schedule and cost implication of a design change before going ahead with the change

7. Freezing design at the appropriate stage of a project or implementing intermediate design freezes at various project stages depending on the type of contract

8. Designing the project to a great detail at the outset whenever possible

9. Provision/allocation of enough resources (labor, equipment, etc) to cope with a design change

10. Design changes should be adequately highlighted and updated on all relevant project documentations (e.g. drawings, specifications, reports etc)
11. Agreeing and putting in place change management procedure before the commencement of projects (incorporating this into the contract if possible)

12. Ensuring prompt resolution to design change queries, issues and authorization requests

13. Capturing all design change on a register with corresponding cost and schedule implication for discussion during project team meetings

14. Having a design manager where possible with responsibility for the management of the design change process and reviewing related information as they come in

15. Ensuring no one makes a design change without the knowledge or authorization of the relevant project party e.g. project manager

16. Open discussion by the relevant project party before the project starts about how design changes will be managed and incorporating this into the contract if possible

17. Efficient analysis of the direct and indirect consequence (domino effect) of a design change on other activities or areas of the project as one change can precipitate other changes.

18. Ensuring design changes are reasonably timed when possible e.g. late design changes may greatly impact the ability to control the project cost and schedule.

\section{Evaluation}

The initial version of the PCIM model and the good practice checklists were evaluated by an expert panel through a Delphi process. The Delphi technique is usually used to obtain the most reliable consensus of opinion of a group of experts by a series of intensive questionnaire Cite as: Olawale, Y. and Sun, M. (2012) PCIM: A project control and inhibiting-factors management model. ASCE Journal of Management in Engineering doi:10.1061/(ASCE)ME.1943-5479.0000125 (Feb. 21, 2012). 
interspersed with controlled opinion feedback. It was initially used by the military to estimate the probable effects of massive atomic bombing but now has applications in economic and financial settings, civic planning, healthcare, etc. (Thangaratinam and Redman, 2005). The Delphi technique has previously been used to achieve similar objective in construction management research. For instance 'Chan A.' et al. (2001) used the Delphi process in the development of model for the selection of a procurement system for construction projects, Manoliadis et al. (2006) used it to determine the drivers of change in the Greek construction industry while Yeung et al (2009) also used it to develop a model that can be used to assess the success of relationshipbased construction projects in Australia.

The experts for the Delphi process in this study were purposely selected based on the following criteria:

- They must have participated in the earlier interviewing process to ensure they have a background of the research and avoid having to explain the usefulness of the research all over, and as this is not a testing process but conceptual validation and final developmental process in the development of the PCIM model. Furthermore, this also has the likelihood of increasing their commitment to see the Delphi process through and reduce one of the widely documented drawbacks of the Delphi technique (experts pulling out before the final round).

- They must have more than 10 years experience in the area of planning and project control/project management of construction projects.

- They must be committed to participate in all the Delphi rounds

Cite as: Olawale, Y. and Sun, M. (2012) PCIM: A project control and inhibiting-factors management model. ASCE Journal of Management in Engineering doi:10.1061/(ASCE)ME.1943-5479.0000125 (Feb. 21, 2012).

Page 29 
Eight practitioners agreed to participate in the Delphi process. All the experts held relevant senior positions in the planning (scheduling) and project management department of their organizations. These experts were also very experienced practitioners with six of the eight experts having more than 25 years of experience. The total experience of the experts is 227 years (average experience of 28 years). All the experts were of the opinion that the PCIM model was suitable or very suitable. All the experts also thought the model is simple or very simple to use and all the experts rated the model being helpful or very helpful for project control. The experts also provided comments and suggestions on how they think the model can be improved. These comments, combined with further literature analysis and information from the wider research, were used to improve the PCIM model.

In addition to the evaluation of the structure of the PCIM model, the Delphi process also seeks to validate the identified good practices and to ascertain the level of significance of each of them. These experts were asked to consider the 65 identified good practices specific to the main control steps (Plan, Monitor, Report, Analyze) and rate them as either critical, important, helpful or unimportant in aiding project cost and time control. Two rounds of Delphi were conducted. The first round of Delphi was basically devoted to getting a first glimpse into how experts feel about the practices put forward to them and seeing if any agreement exists on their significance in the first instance. While the second round of Delphi process was aimed at finding out if the experts can reach a consensus on the rating of the practices. At the end of the second round of Delphi 20 practices were considered “critical”, 34 practices were considered “important” and 11 practices as "helpful". In other words, $83 \%$ of the good practices were considered by majority of the experts as either "critical" or "important" in aiding project control and the remaining $17 \%$ were 
considered "helpful". This result validates their relevance to practitioners and justifies the importance of having a good practice checklist to accompany the developed PCIM model. The Delphi process should not be mistaken as the testing of the model. It serves to provide information on the potential usefulness of the developed model in practice, to ensure it is evaluated by those it is intended for (practitioners) and to validate whether their needs and requirements have truly been taken into consideration within the PCIM model. Testing the model with a real life project is a future research issue as any meaningful case study would be longitudinal in nature due to the process-based and qualitative nature of the model; hence why the "practice grounded" research approach geared at ensuring the practicality of the model was adopted in the first place. In the absence of this, the practical applicability of the model is illustrated in the next section.

\section{Practical value of the PCIM model}

The practical applicability of the PCIM model and its potential benefits can be illustrated using a real world example of a construction firm, for which one of the authors had worked for a year as a project manager. The firm, Company A for anonymity, is involved in commercial construction fit-out projects, which usually last between 3 to 12 months. It employs project managers with varied levels of experience. Each project manager usually handles up to four projects simultaneously depending on project size and complexity. Although the company had an established accounting and financial control system and an ISO certified quality control system in place, it had no standard project control methods. Each project manager adopts ad hoc procedures and decides the type and detail of the schedule at his/her own discretion. In addition, although most of the project managers were trained to degree level and had the relevant 
professional qualifications making them aware of project control techniques like EVA, CPM and S-curves, these techniques were rarely used in the analysis of project progress because of a lack of standardized project control process within the organization. Furthermore, when remedial actions were required, they were usually decided based on experience of the individual project managers rather than on any systematic approach. As a result, delays and cost overruns are common in many projects of Company A. The PCIM model would be beneficial to Company A in a number of ways:

- The model requires a project team to develop a Project Control Implementation Document (PCID) at the outset of the project. This will help to impose a standardized project control procedure, which provides a basis for measuring and improving performance of project controls.

- Adopting the PCIM model would promote proactive culture toward project control in Company A. Project managers will follow a clear process of monitor, review and manage variations of costs and time during projects. The use of good practice checklists and integrated reporting templates will further formalize project control practice throughout the whole Company.

- At present, normal practice of project progress analysis at Company A is by qualitative evaluation of the reported progress against the planned progress and by assessment of subcontractor's invoice in relation to the work package cost budget. Cost and time are often assessed separately; holistic assessment is difficult. The PCIM model addresses this issue by advocating integrated quantitative analysis of cost and time information at all times.

Cite as: Olawale, Y. and Sun, M. (2012) PCIM: A project control and inhibiting-factors management model. ASCE Journal of Management in Engineering doi:10.1061/(ASCE)ME.1943-5479.0000125 (Feb. 21, 2012). 
- The dedicated feedback phase of the PCIM model will ensure that the results of analysis are immediately fed back to the project manager and other team members from whom actions are required. This will lead to prompt actions and timely update of cost and schedule information, avoiding the current situation where schedule of works is updated regularly but cost plan is only revised later for final accounts purposes.

- The PCIM model requires an impact analysis to be conducted on all potential corrective actions by evaluating the potential 'domino effect' of any action and the feasibility of its implementation. This will help project managers to choose the optimum solution rather than the first solution that comes to mind.

- Finally, the use of the PCIM model, especially the good practice checklists will remove the lack of a sense direction and guidance by project managers on best practice to adopt during project control. These checklists will be reviewed periodically to ensure their applicability to the types of project and project stages at the company.

Many of the above practical values of the PCIM model are applicable to the whole construction industry. In addition, the study found that the current ad hoc and fragmented project control practice results in a lack of proactive learning beyond gaining personal experience by individual project managers. The PCIM model aims to standardize the practice of project control within a project team, an organization and the whole construction industry. The standard procedure and guides can be especially useful for less experienced project managers who are new to the profession. Furthermore, the development method used in the development of the PCIM model can be used for further modification and customization. In other words, the model provides a

Cite as: Olawale, Y. and Sun, M. (2012) PCIM: A project control and inhibiting-factors management model. ASCE Journal of Management in Engineering doi:10.1061/(ASCE)ME.1943-5479.0000125 (Feb. 21, 2012).

Page 33 
blueprint for others to develop control process models specific to their own projects, their own organizations and even their own different countries.

\section{CONCLUSIONS}

The PCIM model, with the accompanied good practice checklists, provides a systematic framework and general guidance for project managers to control cost and time of construction projects. It can also be used as a blueprint to develop project specific control model for a particular project. While the steps of the PCIM can be universal for all construction projects, the inhibiting-factors may vary from project to project. The five factors incorporated as part of the PCIM model are identified based on a study conducted in the UK. These leading inhibitingfactors may be different from those of other countries. Indeed, even within a country, there may be variations between different organizations and different types of projects. Therefore, customization of the inhibiting factors and the related good practice checklist is desirable, even essential.

The good practice checklists intend to facilitate the adoption of the PCIM in practice. However, it is important to recognize that other barriers to its adoption may exist and need to be overcome. Firstly, one of such barriers is the need for a cultural change. A successful implementation of the PCIM in a project requires all cost and scheduling professionals of that project to work together. Unfortunately, at present the prevailing culture in the UK construction industry is still poor in collaboration caused by the fragmented organizational structure. Fundamental solution to this problem will require a long term effort to transform the culture of the industry. In the meantime, project managers should be made aware of the potential benefit of PCIM in promoting teamwork

Cite as: Olawale, Y. and Sun, M. (2012) PCIM: A project control and inhibiting-factors management model. ASCE Journal of Management in Engineering doi:10.1061/(ASCE)ME.1943-5479.0000125 (Feb. 21, 2012).

Page 34 
and collaboration. Another barrier is the perceived cost implication of modifying existing systems. Project managers may regard the introduction of new software packages, reporting templates, user training in the use of new techniques as additional costs. Such a fear can be allayed by the fact that the PCIM model is not advocating a total departure from the tangible aspects of project control in practice but seeks to bring a structure into the project control process.

Successful implementation of the PCIM model also relies on management buy-in. Cultural change and realignment of existing processes will not happen without the support of the management of a company. Therefore, it is absolutely essential that senior management is fully behind the implementation of the PCIM model from the very start of a construction project. Managers should instill in the psyche of all employees the need to utilize the model and accompanying good practice checklist; and provide all the necessary support and encouragement in order to realize the full benefits.

It is worth noting some of the limitations of this study, the Delphi method was used during the development and evaluation of the PCIM model. During this process, positive feedback had been received from industry experts about the suitability of the PCIM to practice. However, further testing in real life projects is required before any definitive conclusions can be drawn about the effectiveness of the model in improving project control, although a real life example of how the project can be adopted has been provided. Furthermore, since the focus of the investigation is on construction projects in the UK, the results may not be automatically generalized to construction projects worldwide. In addition, the sample population for the research has come from the 
biggest construction companies and consultancies in the UK. Additional investigation is required to ascertain whether the findings and the developed model will equally apply to the smaller construction organizations. Finally, as previously mentioned, only five project control inhibiting factors have been included as part of the PCIM model because they were found to be the same leading factors for cost and time control during survey of this study. These factors and their number may vary for other types of organizations or different countries. If that is the case, the PCIM model needs to be modified for the new situations.

Cite as: Olawale, Y. and Sun, M. (2012) PCIM: A project control and inhibiting-factors management model. ASCE Journal of Management in Engineering doi:10.1061/(ASCE)ME.1943-5479.0000125 (Feb. 21, 2012). Page 36 


\section{REFERENCES}

1. Alshawi, M., and Hassan, Z., (1999). "Integrated models for construction planning: object flow and relationship Engineering." Construction and Architectural Management, 6 (2), 197-212.

2. Angelides, D. (1999). "Project management and good technical and business practices." Journal of Management in Engineering, 15 (3), 78 - 88.

3. Assaf, S., Al- Khaliil, M., Al-Hazmi, M. (1995). "Causes of delay in Large building construction projects.” Journal of Management in Engineering, 11 (2), 45 - 50.

4. Barraza, G., and Bueno, R. (2007). "Probabilistic control of project performance using control limit curves.” Journal of Construction Engineering and Management, 133 (12), 957 965.

5. Barrie, D. and Paulson, B. (1984). Professional Construction Manager, McGraw-Hill Book Company, New York.

6. Benjaoran, V. (2009). “A cost control system development: A collaborative approach for small and medium-sized contractors.” International Journal of Project Management, 27 (3), $270-277$.

7. Chan, A., Yung, E., Lam, P., Tam, C. and Cheung, S. (2001). “Application of Delphi method in selection of procurement systems for construction projects." Construction Management and Economics, 19 (7), 699 - 718.

8. Chan, D. and Kumaraswamy, M. (1997). “A comparative study of causes of time overruns in Honk Kong construction projects.” International Journal of Project Management, 15 (1), 5563.

9. Chan, P., Ho, D., Tam, C. (2001). “Design and build project success: multivariate analysis.” Journal of Construction Engineering and Management, 127 (2), 93 - 100.

10. Chang, A. (2002). "Reasons for cost and schedule increase for engineering design projects.” Journal of Management in Engineering, 18 (1), 29-36.

11. Cho, K., Hong, T., and Hyun, C. (2010). "Integrated schedule and cost model for repetitive construction process.” Journal of Management in Engineering, 26 (2), 78 - 88.

12. Deming, W. (2000). “Out of Crisis.” MIT Press, Cambridge.

Cite as: Olawale, Y. and Sun, M. (2012) PCIM: A project control and inhibiting-factors management model. ASCE 
13. Egbu, C., Young, B., Torrance, V. (1998). "Planning and control processes and techniques for refurbishment management.” Construction Management and Economics, 16 (3), 315-325.

14. Falco, M., and Macchiaroli, R. (1998). "Timing of control activities in project planning.” International Journal of Project Management, 16 (1), 51 - 58.

15. Fena-Mora, F., and Li, M. (2001). "Dynamic planning and control methodology for design/build fast-track construction projects.” Journal of Construction Engineering and Management 127 (1), 1 - 17.

16. Fewings, P. (2005). Construction Project Management: An Integrated Approach, Taylor and Francis, London.

17. Floyd, L. (2004). “Application of appropriate controls tools for contract type.” Cost Engineering, 46 (2), 25-30.

18. Gao, Z., Smith, G., Minchin, R. (2002). "Budget and schedule success for small capitalfacility projects.” Journal of Management in Engineering, 18 (4), 186 - 193.

19. Gorog, M. (2009). “A comprehensive model for planning and controlling contractor cashflow.” International Journal of Project Management, 27 (5), 481 - 492.

20. Hoffman, G., Thal, A., Webb, T., and Weir, J. (2007). “Estimating Performance Time for Construction Projects.” Journal of Management in Engineering, 23 (4), 193 - 199.

21. Hyari, K., and El-Rayes, K. (2006). “Optimal planning and scheduling for repetitive construction projects.” Journal of Management in Engineering, 22 (1), 11 - 19.

22. Iyer, K., and Jha, K. (2005). "Factors affecting cost performance evidence from Indian construction projects.” International Journal of Project Management, 23 (4), 283-295.

23. Jung, Y., and Kang, S. (2007). "Knowledge-based standard progress measurement for integrated cost and schedule performance control.” Journal of Construction Engineering and Management, 133 (1), 10-21.

24. Jung, Y. and Woo, S. (2004). "Flexible work breakdown structure for integrated cost and schedule control.” Journal of Construction Engineering and Management, 130 (5), 616 625.

25. KaKa, A. (1999). "The development of a benchmark model that uses historical data for monitoring the progress of current construction projects." Engineering, Construction and Architectural Management, 6 (3), 256-266.

Cite as: Olawale, Y. and Sun, M. (2012) PCIM: A project control and inhibiting-factors management model. ASCE Journal of Management in Engineering doi:10.1061/(ASCE)ME.1943-5479.0000125 (Feb. 21, 2012). Page 38 
26. Lee, S., Thomas, S., Tucker, R., (2005). "The relative impacts of selected practices on project cost and schedule.” Construction Management and Economics, 23, 545-553.

27. Leu, S., and Lin, Y. (2008). "Project performance evaluation based on statistical process control techniques.” Journal of Construction Engineering and Management, 134 (10), 813 819.

28. Ling, F. (2004). "How project managers can better control the performance of design-build projects.” International Journal of Project Management, 22 (6), 477-488.

29. Ling, Y., Low, S., Wang, S., and Lim, H., (2009). "Key project management practices affecting Singaporean firms' project performance in China.” International Journal of Project Management, 27 (1), 59 -71.

30. Manoliadis, O., Tsolas, I., and Nakou, A. (2006). "Sustainable construction and drivers of change in Greece: A Delphi study.” Construction Management and Economics, 24 (2), 113 120.

31. Mawdesley, M., Askey, W., O’Reilly, M. (1997). Planning and controlling construction projects: The best laid plans, Englemere Services Ltd., Ascot.

32. Milosevic, D., and Patanakul, P. (2005). "Standardized project management may increase development projects success.” International Journal of Project Management, 23 (3), 181 192.

33. Nassar, K., Nassar, W., and Hegab, M. (2005). "Evaluating cost overruns of asphalt paving projects using statistical process control methods.” Journal of Construction Engineering and Management, 131 (11), 1173 -1178.

34. Olawale, Y., and Sun M. (2010). "Cost and time control of construction projects: Inhibiting factors and mitigating measures in practice.” Construction Management and Economics, 28 (5), $509-526$.

35. Otieno, F. (2000). “The roles of monitoring and evaluation in projects." $2^{\text {nd }}$ International Conference on Construction in Developing Countries: Challenges facing the construction industry in developing countries, 15-17 November 2000, Gabarone, Botswana.

36. Pellicer, E. (2005). “Cost control in consulting engineering firms.” Journal of Management in Engineering, 21 (4), 189 - 192.

Cite as: Olawale, Y. and Sun, M. (2012) PCIM: A project control and inhibiting-factors management model. ASCE Journal of Management in Engineering doi:10.1061/(ASCE)ME.1943-5479.0000125 (Feb. 21, 2012).

Page 39 
37. Platje, A. and Wadman, S. (1998). "From Plan-Do-Check-Action to PIDCAM: The further evolution of the Deming-wheel.” International Journal of Project Management, 16 (4), 201208.

38. Rozenes, S., Vitner, G., and Spraggett, S. (2006). "Project control: Literature review." Project Management Journal, 37 (4) 4 - 14.

39. Rozenes, S., Vitner, G., Spraggett, S. (2004). “MPCS: Multidimensional Project Control System.” International Journal of Project Management, 22 (2), 109 - 118.

40. Shane, J., Molenaar, K., Anderson, S., and Schexnayder, C. (2009). “Construction project cost escalation factors.” Journal of Management in Engineering, 25 (4), 221 - 229.

41. Sohail, M., Baldwin, A. (2004). "Performance indicators for micro-projects in developing countries.” Construction Management and Economics, 22 (1), 11-23.

42. Thangaratinam, S. and Redman, C. (2005). “The Delphi Technique.” The Obstetrician and Gynecologist, 7 (2), 120 - 125.

43. Turner, J. (1999). The handbook of project-based management, McGraw-Hill Companies, London.

44. Vandevoorde, S., and Vanhoucke, M. (2005). “A comparison of different project duration forecasting methods using earned value metrics." International Journal of Project Management, 24 (4), 289-302.

45. Watson, P. and Davis, R. (2002). “Applying Dr Deming's dynamic control model to project cost control." Proceedings of the RICS Foundation construction and building research conference, 5-6 September 2002, Nothingham Trent University, UK.

46. White, D., and Fortune, J. (2002). "Current practice in project management - An empirical study.” International Journal of Project Management, 20(2), 1 - 11.

47. Xiao, H., and Proverbs, D. (2002). "Construction time performance: an evaluation of contractors from Japan, the UK and the US.” Engineering, Construction and Architectural Management, (9) 2, 81-89.

48. Yakubu O., and Sun, M. (2009). "Cost and time control of construction projects: A survey of contractors and consultants in the UK.” Construction Information Quarterly, 11 (2), 53 - 59.

Cite as: Olawale, Y. and Sun, M. (2012) PCIM: A project control and inhibiting-factors management model. ASCE Journal of Management in Engineering doi:10.1061/(ASCE)ME.1943-5479.0000125 (Feb. 21, 2012). Page 40 
49. Yeung, J., Chan, P., and Chan, D. (2009). “Developing a performance index for relationshipbased construction projects in Australia: Delphi Study.” Journal of Management in Engineering, 25 (2) 59 - 67. 